\title{
Electrophilic Fluorination Using A Hypervalent Iodine Reagent Derived From Fluoride $\uparrow$
}

\author{
Gemma C. Geary, Eric G. Hope, Kuldip Singh and Alison M. Stuart* \\ Received (in $X X X, X X X)$ Xth $X X X X X X X X X 20 X X$, Accepted Xth $X X X X X X X X X 20 X X$ \\ ${ }_{5}$ DOI: 10.1039/b000000x
}

The air and moisture stable fluoroiodane 8 , readily prepared on a $6 \mathrm{~g}$ scale by nucleophilic fluorination of the hydroxyiodane 7 with TREAT-HF, has been used as an electrophilic fluorinating reagent for the first time to 10 monofluorinate 1,3-ketoesters and difluorinate 1,3-diketones in good isolated yields.

In late 2011, Ritter reported the first electrophilic fluorination using the fluoride anion in a transfer fluorination between two palladium species. ${ }^{1}$ An alternative, non-metal based strategy 15 could be envisaged using cyclic hypervalent iodine(III) compounds which have been shown to be mild, non-toxic and selective reagents for halogenation..$^{2-4}$ These reagents are normally prepared by oxidation of iodine(I) species with electrophilic reagents such as tert-butyl hypochlorite $(\mathbf{1} \rightarrow \mathbf{3})$ and ${ }_{20} \mathrm{~N}$-bromosuccinimide $(\mathbf{1} \rightarrow \mathbf{2}),{ }^{2}$ but Togni cleverly designed the synthesis of the electrophilic trifluoromethylated hypervalent iodine reagent 5 using a formal umpolung of the trifluoromethyl group (Scheme 1). ${ }^{3 a}$ Ruppert's reagent was used as the nucleophilic source of the trifluoromethyl anion in order to 25 displace the acetate and form an electrophilic trifluoromethylating reagent. Togni's reagent now has widespread applications including the electrophilic trifluoromethylation of $\beta$-ketoesters, $\alpha$-nitroesters, thiols, phosphines and heteroaromatic compounds. ${ }^{3}$ Using an analogous nucleophilic 30 route, $\mathrm{Lu}$ and Shen reported in 2013 the new electrophilic hypervalent iodine reagent $\mathbf{6}$ for the trifluoromethylthiolation of $\beta$-ketoesters, alkynes, aryl and vinyl boronic acids. ${ }^{4}$

Our research group is interested in designing new methods for introducing fluorine into organic molecules ${ }^{5}$ because of the 35 importance of incorporating fluorine into drug candidate molecules. ${ }^{6}$ Since Banks first reported SelectFluor in $1992,{ }^{7}$ the fluoraza reagents have become increasingly popular electrophilic fluorinating reagents because they are commercially-available, shelf-stable powders that can be used to fluorinate a wide variety 40 of substrates. ${ }^{8}$ The main disadvantage of these electrophilic fluorinating reagents, however, is that they are very expensive because they are normally made from elemental fluorine.

Department of Chemistry, University of Leicester, Leicester, LE1 7RH,

45 UK. Fax: +44 (0)116 2523789; Tel: +44 (0)116 2522136; E-mail:

Alison.Stuart@le.ac.uk

$\dagger$ Electronic Supplementary Information (ESI) available: Experimental procedures, NMR spectra and crystallographic data in CIF or other electronic format see DOI: $10.1039 / \mathrm{b} 000000 \mathrm{x} /$

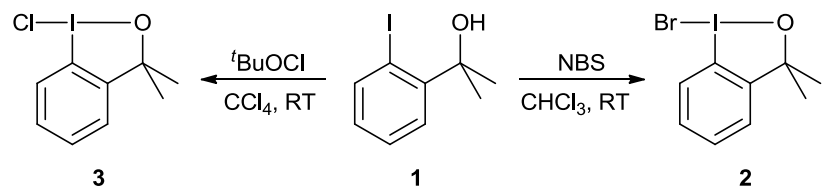<smiles>CC1(C)OI(Cl)c2ccccc21</smiles>

3

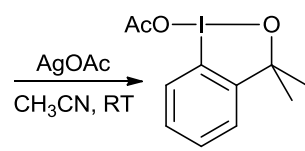

4

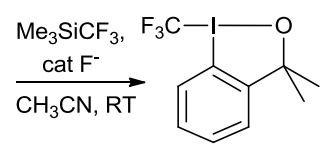

5

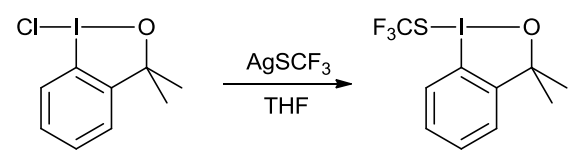

3

50 Scheme 1 Syntheses of hypervalent iodine reagents

Alternative reagents such as (difluoroiodo)arenes have been prepared from aqueous $\mathrm{HF}$, but they are extremely moisture sensitive and are commonly used as a freshly prepared solution, without isolation, or they can be generated in situ. ${ }^{9}$ Inspired by ${ }_{55}$ Togni's seminal work on electrophilic trifluoromethylation, ${ }^{3}$ we were interested in developing a new class of stable fluorinating reagents based on the cyclic hypervalent iodine(III) skeleton, but generated from cheap sources of fluoride. Here, we will report three different methods for the preparation of an air and moisture 60 stable fluorinated hypervalent iodine reagent $\mathbf{8}$ and preliminary results on its' fluorination of a series of 1,3-dicarbonyl substrates.<smiles>CC(C)(O)c1ccccc1I</smiles>

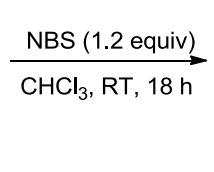<smiles>CC1(C)OI(Br)c2ccccc21</smiles>

2

(79\% yield) $\downarrow \begin{aligned} & \mathrm{KOH}_{\text {(aq) }} \text { (2 equiv) } \\ & \mathrm{CH}_{2} \mathrm{Cl}_{2}, \mathrm{RT}, 2 \mathrm{~h}\end{aligned}$

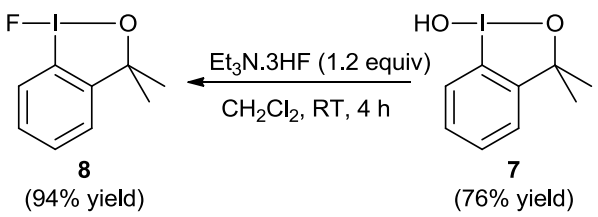

Scheme 2 Synthesis of the fluoroiodane 8 using TREAT-HF 
<smiles>CC(C)(O)c1ccccc1I</smiles><smiles>CCOC(=O)OCCCC(C)C(C)(C)C(=O)OCC</smiles>

1<smiles>CC(C)(O)c1ccccc1I</smiles>

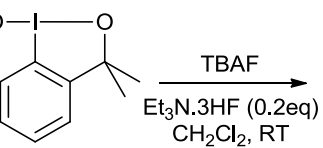

\% yield)

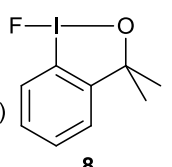

(63\% yield)

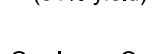

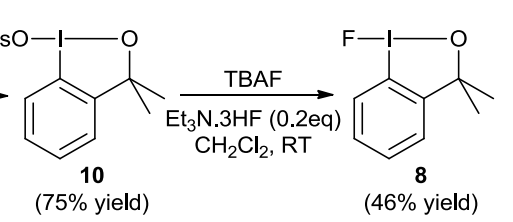

Scheme 3 Syntheses of the fluoroiodane 8 using TBAF

The fluoroiodane $\mathbf{8}$ was first prepared in 2012 by the electrophilic fluorination of 2-(2-iodophenyl)propan-2-ol $\mathbf{1}$ with 1.3 equivalents of Selectfluor in acetonitrile. ${ }^{10}$ Whilst this manuscript was 5 in the final stages of preparation, Togni reported a nucleophilic route to the fluoroiodane $\mathbf{8}$ by halogen exchange of the chloroiodane 3 with 1.5 equivalents of spray-dried potassium fluoride in acetonitrile, ${ }^{11}$ but both the reaction and the work up were carried out under argon. We have developed an alternative 10 three step synthesis that also uses a nucleophilic fluorination (Scheme 2). The bromoiodane 2 , synthesised using $N$-bromosuccinimide, was reacted with potassium hydroxide at room temperature in order to produce the hydroxyiodane 7 under mild reaction conditions. In the key step the hydroxyiodane 7 was 15 reacted with 1.2 equivalents of triethylamine tris(hydrogen fluoride) (TREAT-HF) at room temperature to give the fluoroiodane 8 in a $94 \%$ isolated yield after recrystallization from hexane. This is an excellent method for the preparation of $\mathbf{8}$ because there are no time-consuming purifications by column 20 chromatography, each of the steps have been performed routinely on a 6-10 g scale and the reactions do not require either dry or inert conditions.

Since one of the long term aims of this project is to prepare a new fluorinating agent that is suitable for the production of ${ }^{18} \mathrm{~F}$ 25 labelled radiotracers for Positron Emission Tomography (PET) imaging, we were also interested in developing a nucleophilic route to the fluoroiodane $\mathbf{8}$ using sources of fluoride, such as potassium fluoride or tetrabutylammonium fluoride (TBAF), that can be applied to PET chemistry. Our synthetic strategy was to 30 introduce a good leaving group onto the hypervalent iodine reagent in order to facilitate nucleophilic displacement by fluoride (Scheme 3). To this end, the new hypervalent iodine reagents, trifluoroacetoxyiodane $\mathbf{9}$ and tosyliodane 10, were synthesised by the reaction of 2-(2-iodophenyl)propan-2-ol $\mathbf{1}$ 35 with either $\mathrm{PhI}\left(\mathrm{OCOCF}_{3}\right)_{2}$ or $\mathrm{PhI}(\mathrm{OH})(\mathrm{OTs})$ following Koser's procedure $^{12}$ and the solid-state structures of both compounds are presented in the supplementary information. When the trifluoroacetoxyiodane 9 was reacted with 1.2 equivalents of TBAF in dichloromethane, a mixture of the fluoroiodane $\mathbf{8}$ and 40 the hydroxyiodane 7 was obtained in a 3:1 ratio. Since neither 9 nor $\mathbf{8}$ are hydrolysed in the presence of water, the formation of the hydroxyiodane 7 is believed to be due to the presence of tetrabutylammonium hydroxide in the TBAF. Therefore, since tetrabutylammonium hydroxide reacts with aqueous $\mathrm{HF}$ to give ${ }_{45} \mathrm{TBAF}^{13}$ and the hydroxyiodane 7 reacts with TREAT-HF to
Table 1 Optimisation of fluorination of ethyl-3-oxo-3-phenylpropanoate

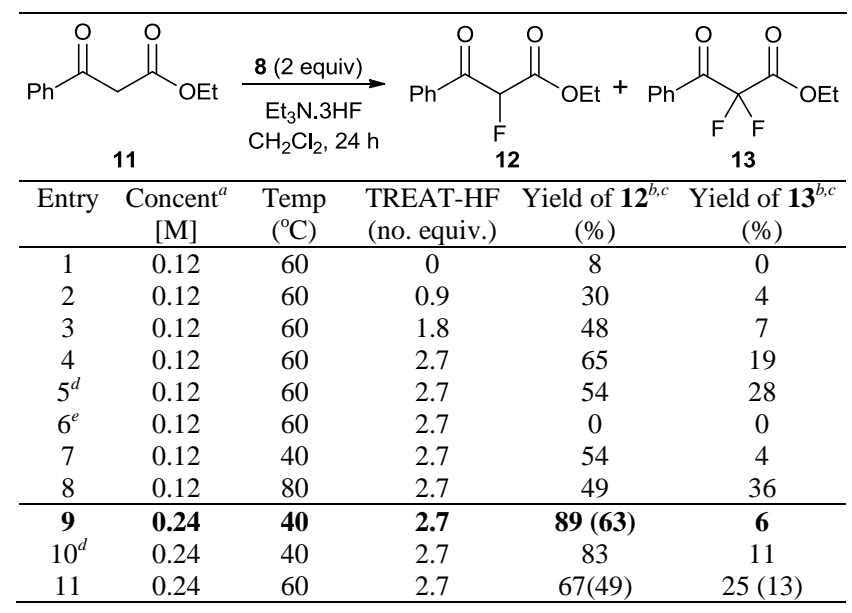

${ }^{a}$ Concentration of substrate. ${ }^{b}$ Determined by ${ }^{1} \mathrm{H}$ and ${ }^{19} \mathrm{~F}$ NMR spectroscopy. ${ }^{c}$ Isolated yield in parenthesis. ${ }^{d}$ Reaction time was $48 \mathrm{~h}$. ${ }^{e}$ Control reaction without fluoroiodane 8 .

50 form the fluoroiodane $\mathbf{8}$, the addition of TREAT.HF was investigated. With just 0.2 equivalents of TREAT-HF (Scheme 3 ) the fluoroiodane $\mathbf{8}$ was isolated in a $63 \%$ yield on a $1.0 \mathrm{~g}$ scale. The reaction between the tosyliodane $\mathbf{1 0}$ and TBAF in the presence of TREAT-HF was also successful giving a $100 \%$ 55 conversion to the fluoroiodane 8 and a $46 \%$ yield after recrystallization from hexane. Neither the trifluoroacetoxyiodane $\mathbf{9}$ nor the tosyliodane $\mathbf{1 0}$ react with TREAT-HF (1.2 equivalents) at room temperature and in both cases unreacted starting material was recovered at the end of the reaction showing that it is the ${ }_{60}$ fluoride ion from the TBAF that is undergoing the nucleophilic substitution to form the fluoroiodane $\mathbf{8}$.

The reactivity of the fluoroiodane $\mathbf{8}$ as an electrophilic fluorinating reagent was first investigated using ethyl 3-oxo-3phenylpropanoate $\mathbf{1 1}$ as the model substrate (Table 1). When 2 65 equivalents of the fluoroiodane $\mathbf{8}$ was reacted with ethyl 3-oxo-3phenylpropanoate 11 at $60{ }^{\circ} \mathrm{C}$ for 24 hours (entry 1), only an $8 \%$ conversion to the monofluorinated product $\mathbf{1 2}$ was obtained. The addition of TREAT-HF is essential for the fluorination and on increasing the amount from 0.9 to 2.7 equivalents the conversion 70 to both the monofluorinated and difluorinated products increased to $65 \%$ and $19 \%$ respectively (entry 4 ). On extending the reaction time to 48 hours in entry 5 , more of the difluorinated product $\mathbf{1 3}$ was produced. However, the fluorination of ethyl 3-oxo-3phenylpropanoate 11 with 2.7 equivalents of TREAT-HF does 75 not proceed in the absence of the fluoroiodane $\mathbf{8}$ (entry 6). Interestingly, the temperature of the reaction is an important factor with a more selective reaction towards the monofluorinated product 12 observed at $40{ }^{\circ} \mathrm{C}$ (entry 7), whilst the amount of the competing difluorinated product 13 increased at $80^{\circ} \mathrm{C}$ (entry 8).

80 The concentration of the reaction mixture is also an important factor in these fluorinations. When the concentration of the substrate was doubled from $0.12 \mathrm{M}$ to $0.24 \mathrm{M}$, there was a dramatic improvement in the fluorination performed at $40{ }^{\circ} \mathrm{C}$ and the conversion to the monofluorinated product $\mathbf{1 2}$ increased from ${ }_{85} 54 \%$ (entry 7) to $89 \%$ (entry 9). The reaction was purified by column chromatography and ethyl 2-fluoro-3-oxo-3-phenylpropanoate 12 was isolated in $63 \%$ yield. When either the reaction time was extended to 48 hours (entry 10) or the reaction 


\section{Cite this: DOI: $10.1039 / \mathrm{c0xx00000x}$}

Table 2 Fluorination of 1,3-dicarbonyl compounds ${ }^{a}$

Entry

${ }^{a}$ Reaction conditions: substrate $(0.72 \mathrm{mmol})$, fluoroiodane $8(1.44 \mathrm{mmol})$, $\mathrm{Et}_{3} \mathrm{~N} .3 \mathrm{HF}(1.94 \mathrm{mmol})$ and dry $\mathrm{CH}_{2} \mathrm{Cl}_{2}(1.2 \mathrm{~mL}) .{ }^{b}$ Determined by ${ }^{1} \mathrm{H}$ and ${ }^{19} \mathrm{~F}$ NMR spectroscopy. ${ }^{c}$ Isolated yield in parenthesis. ${ }^{d}$ Fluoroiodane 8 (3 5 equiv). ${ }^{e}$ No solvent.

was performed at $60{ }^{\circ} \mathrm{C}$ (entry 11), the amount of ethyl 2,2difluoro-3-oxo-3-phenylpropanoate 13 increased.

The scope of the reaction was established with a series of 1,3dicarbonyl compounds and the results are presented in Table 2.

10 The relative reactivity of the different substrates could be directly correlated with their enol content as observed previously for electrophilic fluorinations. ${ }^{7 \mathrm{c}, 14}$ When ethyl 3-(4-methoxyphenyl)3-oxo-propanoate was reacted with the fluoroiodane $\mathbf{8}$ under the optimum reaction conditions from Table 1 (entry 9: $40{ }^{\circ} \mathrm{C}, 24$ 15 hours), the monofluorinated product was isolated in $67 \%$ yield (entry 2). Under the same reaction conditions the more reactive substrate, 1,3-diphenyl-1,3-propanedione (entry 3), gave a mixture of the monofluorinated (30\%) and difluorinated $(55 \%)$ products. In order to convert the 1,3-diketone into the difluorin20 ated product, the reaction was repeated at $60{ }^{\circ} \mathrm{C}$ for 24 hours but there was still a small amount of the monofluorinated product present $(11 \%)$ at the end of the reaction. Finally, the reaction was repeated with 3 equivalents of the fluoroiodane 8 at $60{ }^{\circ} \mathrm{C}$ resulting in a $100 \%$ conversion to 1,3-diphenyl-2,2-difluoro-1,325 propanedione which was isolated in $71 \%$ yield. The other 1,3diketone, 1-phenyl-1,3-butanedione (entry 4), was also reacted with 3 equivalents of the fluoroiodane 8 at $60{ }^{\circ} \mathrm{C}$ for 24 hours producing 1-phenyl-2,2-difluoro-1,3-butanedione in $45 \%$ yield. Due to its extremely low enol content $\left(100 \%\right.$ ketone in $\mathrm{CDCl}_{3}$ by ${ }_{30}{ }^{1} \mathrm{H}$ NMR spectroscopy), the fluorination of the monosubstituted 1,3-ketoester, ethyl 2-methyl-3-oxo-3-phenylpropanoate (entry 5) took 7 days at $60{ }^{\circ} \mathrm{C}$ without solvent to give the fluorinated product in 55\% isolated yield. On the other hand, the fluorination of ethyl 1-indanone-2-carboxylate was much more efficient and $35100 \%$ conversion to ethyl 1 -indanone-2-fluoro-2-carboxylate was obtained in 48 hours (55\% yield) because of its higher enol content (17\% in $\mathrm{CDCl}_{3}$ by ${ }^{1} \mathrm{H}$ NMR spectroscopy).

In summary, we have prepared fluoroiodane $\mathbf{8}$ by three different methods using either TREAT-HF or TBAF as the source 40 of the fluoride ion. Preliminary reactivity studies have revealed that it can be used to fluorinate 1,3-diketones and 1,3-ketoesters in good isolated yields and we are currently investigating further applications of $\mathbf{8}$ as an electrophilic fluorinating reagent with a range of different organic substrates.

\section{${ }_{45}$ Notes and references}

1 E. Lee, A. S. Kamlet, D. C. Powers, C. N. Neumann,. G. B. Boursalian, T. Furuya, D. C. Choi, J. M. Hooker, T. Ritter, Science, 2011, 334, 639.

2 D. C. Braddock, G. Cansell, S. A. Hermitage, A. J. P. White, Chem. $50 \quad$ Commun., 2006, 1442.

3 (a) P. Eisenberger, S. Gischig, A. Togni, Chem. Eur. J., 2006, 12, 2579; (b) I. Kieltsch, P. Eisenberger, A. Togni, Angew. Chem. Int. Ed., 2007, 46, 754; (c) P. Eisenberger, I. Kieltsch, N. Armanino, A. Togni, Chem. Commun., 2008, 1575; (d) M. S. Wiehn, E. V. 55 Vinogradova, A. Togni, J. Fluorine Chem., 2010, 131, 951; (e) K. Niedermann, N. Frueh, E. Vinogradova, M. S. Wiehn, A. Moreno, A. Togni, Angew. Chem. Int. Ed., 2011, 50, 1059; (f) N. Santschi, A. Togni, J. Org. Chem., 2011, 76, 4189; $(g)$ K. Niedermann, N. Frueh, R. Senn, B. Czarniecki, R. Verel, A. Togni, Angew. Chem. Int. Ed., 2012, 51, 6511.

4 X. Shao, X. Wang, T. Yang, L. Lu, Q. Shen, Angew. Chem. Int. Ed., 2013, 52, 3457.

5 (a) M. Fornalczyk, K. Singh, A. M. Stuart, Chem. Commun., 2012, 48, 3500; (b) M. Fornalczyk, K. Singh, A. M. Stuart, Org. Biomol. 65 Chem., 2012, 10, 3332.

6 (a) S. Purser, P. R. Moore, S. Swallow, V. Gouverneur, Chem. Soc. Rev., 2008, 37, 320; (b) D. O'Hagan, J. Fluorine Chem., 2010, 131, 1071.

7 (a) R. E. Banks, S. N. Mohialdin-Khaffaf, G. S. Lal, I. Sharif, R. G. 70 Syvret, J. Chem. Soc., Chem. Commun., 1992, 595; (b) G. S. Lal, J. Org. Chem., 1993, 58, 2791; (c) R. E. Banks, N. J. Lawrence, A. L. Popplewell, J. Chem. Soc., Chem. Commun., 1994, 343.

8 (a) G. S. Lal, G. P. Pez, R. G. Syvret, Chem. Rev., 1996, 96, 1737; (b) S. D. Taylor, C. C. Kotoris, G. Hum, Tetrahedron, 1999, 55, 75 12431; (c) R. P. Singh, J. M. Shreeve, Acc. Chem. Res., 2004, 37, 31; (d) P. T. Nyffeler, S. G. Durón, M. D. Burkart, S. P. Vincent, C.-H. Wong, Angew. Chem. Int. Ed., 2005, 44, 192.

9 (a) S. Hara, M. Sekiguchi, A. Ohmori, T. Fukuhara, N. Yoneda, Chem. Commun., 1996, 1899; (b) M. Sawaguchi, S. Ayuba, S. Hara, Synthesis, 2002, 1802; (c) M. A. Arrica, T. Wirth, Eur. J. Org. Chem., 2005, 395; (d) T. Kitamura, S. Kuriki, M. H. Morshed, Y. Hori, Org. Lett., 2011, 13, 2392.

10 C. Y. Legault, J. Prévost, Acta Cryst., 2012, E68, o1238.

11 V. Matoušek, E. Pietrasiak, R. Schwenk, A. Togni, J. Org. Chem., 2013, 78, 6763.

12 G. A. Rabah, G. F. Koser, Tetrahedron Lett., 1996, 37, 6453.

13 I. Kuwajima, E. Nakamura, K. Hashimoto, Org. Synth., 1990, Coll. Vol. 7, 512.

14 L. Hintermann, A. Togni, Angew. Chem. Int. Ed., 2000, 39, 4359. 